\title{
Advantages of an ICF-Based Approach in School Reintegration of Pediatric Brain Tumor Patients: The School Participation Scales (S-PS-24/7)
}

\author{
Thomas Pletschko ${ }^{1}$, Sheena Gmoser ${ }^{2}$, Linda Leeb ${ }^{2}$, Agathe Schwarzinger ${ }^{1}$, Irene Slavc ${ }^{1}$, Ulrike Leiss ${ }^{1}$ \\ ${ }^{1}$ Department of Pediatrics and Adolescent Medicine, Medical University of Vienna, Vienna, Austria; ${ }^{2}$ Faculty of Psychology, Uni- \\ versity of Vienna, Vienna, Austria. \\ Email: thomas.pletschko@meduniwien.ac.at
}

Received April 22 $2^{\text {nd }}, 2013$; revised May 21 ${ }^{\text {st }}, 2013$; accepted May 29 $9^{\text {th }}, 2013$

Copyright (C) 2013 Thomas Pletschko et al. This is an open access article distributed under the Creative Commons Attribution License, which permits unrestricted use, distribution, and reproduction in any medium, provided the original work is properly cited.

\begin{abstract}
Survivors of pediatric central nervous system (CNS) cancer are at risk for long term sequelae concerning school participation. Therefore, the purpose of the study was to develop and evaluate a school-participation questionnaire for patients and parents based on the International Classification of Functioning, Disability and Health (ICF). The items of the School Participation Scales-24/7 (S-PS-24/7) meet different functions, activities and participation aspects, as well as environmental factors listed in the ICF, using everyday language. The study sample consisted of 48 pediatric brain tumor patients and their parents. Reliability scores for the S-PS-24/7 components were acceptable or high. For investigating validity, items were correlated with data from a neurocognitive assessment battery with promising results. This approach enables a description of educational outcome on a functional level instead of using global measures. This facilitates counseling of patients, parents and teachers with respect to academic achievement and specific intervention programs.
\end{abstract}

Keywords: Neurocognitive Outcome; School Reintegration; CNS-Tumors; Participation; ICF

\section{Introduction}

Due to the development of better treatment options, about three out of four children now survive tumors of the central nervous system (CNS). Thus, questions concerning participation in school life and academic achievement become a paramount issue. Because CNS tumors are the largest group of solid tumors in childhood (with a prevalence of two to three children out of 100,000 ), there is the need to provide support to this specific patient group to help them grow up adequately. Unfortunately, the variability of possible illness- and treatment-related late effects is high and may include medical, cognitive, behavioral and psychosocial impairments. Survivors of CNS tumors are at an especially high risk for neurocognitive long-term sequelae, which in turn affect their performance at school. Barrera [1] illustrated this problem by conducting a retrospective multicenter-study including 800 survivors of childhood cancer $(15.2 \%$ CNS tumors) as well as 923 controls. The authors reported that nearly $20 \%$ of all childhood cancer survivors received special educational services compared to $8 \%$ of controls.
Survivors of CNS tumors were most likely to attend special educational programs. Furthermore, Mitby [2] found that survivors had to repeat a grade more often than healthy controls $(21 \%$ vs. $9 \%)$. Stam, Grootenhuis and Last [3] went even further and reported that survivors of childhood cancer achieved fewer developmental milestones or achieved them when they were older than their peers. Taking all these studies into account, the results highlight the importance of reintegrating patients into school. The purpose is not only to facilitate the patients' development and attainment of academic skills, but also to positively affect their self-esteem and social relationships.

However, so far it has not been possible to describe a distinct neuropsychological profile that is specific to a certain type or location of brain tumor. Therefore, each patient must be treated according to individual strengths and difficulties when it comes to interventions concerning school integration and participation programs.

Unfortunately, over the past decades numerous studies have focused solely on global intellectual functioning 
without taking into account single cognitive domains (e.g. processing speed, memory, divided attention). Many of these studies reported a decline in overall intelligence in those patients (e.g. [4-6]). Still, this approach influences the scientific discussion. Moreover, our clinical experience shows that patients are highly concerned. Poggi [7] assessed 74 pediatric brain tumor patients $(52.6 \%$ medulloblastoma, $17.1 \%$ ependymoma, $10.5 \%$ astrocytoma, $19.7 \%$ others) with the Wechsler Intelligence Scales. The results showed a greater impairment in the performance intelligence quotient (PIQ) than in the verbal intelligence quotient (VIQ). The authors found correlations between the time since diagnosis and the severity of cognitive impairment: the longer the time since diagnosis, the higher the loss of IQ points (cf. also [8,9]). Spiegler [10] carried out a longitudinal study, including 34 children treated for posterior fossa tumors. The results showed a linear IQ decline of 2 to 4 points every year. Mulhern [11] investigated the influence of age at diagnosis and dosage of radiotherapy in children treated for medulloblastoma. The higher radiation-dosage group showed a significant decline in intelligence scores, whereas no decline was found in the lower radiation-dosage group. In addition to these results, the authors demonstrated influences of age at diagnosis: children who were younger at time of diagnosis achieved significantly lower intelligence scores than older children.

On the contrary, in recent years a trend can be observed towards a more individualized approach regarding outcome and specific cognitive domains. In fact, this also meets the concerns of the patients. Studies relate to single neurocognitive functions rather than global intellectual impairment. Nagel [12] demonstrated problems in verbal memory in children treated for medulloblastoma. The patients showed insufficient strategies in the encoding and retrieval of information. Substantially lower scores were found in immediate and delayed recall and, less severely, in recognition. Kiehna [13] evaluated changes in the attentional performance of pediatric brain tumor patients before, during and up to 60 months after radiation therapy. The results indicated that patients showed mild inattentiveness before irradiation. Impulsivity, reaction time and overall index score were within normal range. During irradiation they became less impulsive. After irradiation a significant increase in inattentiveness occurred. Furthermore, Mabbott [14] evaluated the impact of treatment on information processing speed in pediatric patients treated for posterior fossa tumors. The sample consisted of patients receiving either a combination of surgery and cranial radiation or surgery without radiotherapy. In addition, a comparison group of patients treated for non-CNS solid tumors was investigated. The results clearly showed poorer information processing speed in patients treated with radiation. In this context it should be pointed out that a general decline in IQ may be due to impairments in specific neurocognitive functions [15]. However, many global intelligence tests (like the Wechsler Scales) require a high processing speed, i.e. in order to achieve a good performance, children have to solve a task very quickly. As mentioned above, radiotherapy negatively affects processing speed [14]. Therefore, interpreting a loss of IQ points as a decrease in overall intelligence may be a false conclusion. In recent years, many more studies focused on neurocognitive outcome of pediatric brain tumor survivors on a functional rather than a global level. Nevertheless, still in 2010 Robinson [16] concluded in their meta-analysis that a broader consideration of multiple domains and use of well-validated measures are important.

Although studies so far have revealed how important it was to focus on the impact of single neurocognitive functions, environmental influences have been largely disregarded. Out of the complexity of this issue, research seemed to be a slow promotor of change. Among the few studies worth mentioning in this context is the one conducted by Vannatta [17]. In 1998 it was already their focus to investigate the acceptance of pediatric cancer survivors within the class community/their peer group. They compared a group of brain tumor survivors to a healthy control group. They arranged the groups according to gender and classroom and collected information via peer, teacher and self-reports. In all three ratings the brain tumor survivor was described as socially more isolated compared to classmates. Additionally, peers and teachers attributed to them characteristics such as being sick, fatigued, and frequently absent from school. Finally, students had to indicate their best friends within the classroom community. They selected brain tumor patients less often than others. Furthermore, Barrera [1] stated that $19 \%$ of pediatric cancer survivors had no close friendships as compared to $8 \%$ of controls. As a consequence, many past and recent reviews suggest to implement specialized educational interventions and schoolbased accommodations to optimize the development of the patients $[16,18]$. Furthermore, this is not only true for pediatric brain tumor patients, but also for children with other chronic health conditions. Especially Canter and Roberts [19] highlight the critical need for more empirical work in this area.

To sum up, the existing approaches do not focus on linking neurocognitive strengths and difficulties with the possibility of participating in everyday school life. This could explain why many patients still face a great many hurdles in their attempt to lead a normal life. Therefore, there is the need to develop strategies to enhance reintegration of pediatric brain tumor patients. 
Delving deeper into this issue, we have found that the International Classification of Functioning, Disability and Health (ICF; WHO) [20] provided a special framework for neuropsychological rehabilitation in a broader sense. According to the ICF, an individual's functioning does not only depend on certain body functions, but also on the possibilities to actively participate in everyday life. The advantage of the ICF is that it includes personal as well as environmental factors. Unfortunately, so far very few attempts have been made to use the ICF framework for pediatric brain tumor patients, especially when it came to a neuropsychological perspective and school integration. Some studies (e.g. [21]) used the ICF to focus on social relationships, others to discuss participation of disabled children in general (e.g. [22]). Furthermore, the existing approaches mainly try to link widely used assessments to the ICF without using the ICF itself as a method for gathering knowledge about the individual patient $[23,24]$. In these attempts, the ICF often serves as checklist or as a mapping of disabilities.

In contrast, in the present study we developed an ICFbased assessment tool that is specific for neuropsychological long-term sequelae after childhood brain injuries: the School Participation Scales (S-PS-24/7), which consists of a self-report and a parent-report questionnaire. 24/7 stands for participation 24 hours a day, 7 days a week. The purpose of this tool is to inquire about resources concerning participation in everyday life. A large part of the ICF (body functions, as well as activities and participation) is covered by questions about day-to-day situations. Even though the focus remaine a neuropsychological one, we include social aspects of school integration too. The questionnaires therefore inquire about social support from teachers and peers at school. By doing so, the S-PS-24/7 addresses personal as well as environmental factors and tries to overcome the disadvantages of the previously reported attempts of using the ICF. Consequently, the research questions of the present study are:

- Are the S-PS-24/7 a reliable and valid tool for the screening of neurocognitive functions as well as for the possibility to participate in daily life?

- Does the internal structure of the S-PS-24/7 reflect the structure given by the ICF?

- How can pediatric brain tumor patients be described according to the new measurement tool?

\section{Methods}

\subsection{Measures}

In order to overcome the abovementioned disadvantages, the body functions (especially mental functions), classifications of activities and participation as well as the en- vironmental factors as listed in the ICF provided the basis for item construction. The selection process contained three steps: 1) A review of relevant literature on pediatric brain tumor patients which revealed a list of neuropsychological aspects that seem to be of importance when discussing possibilities for school (re-)integration; 2) Clinical experience of the authors working in the field of neurooncologic aftercare led to a second list of relevant functions, activities and environmental factors; 3) The equivalences between the two lists were compared with the ICF. Finally, all functions that corresponded to the ICF were chosen for item construction. In single cases, where no correspondence could be found in the ICF, we used the category "other specified" at the end of each ICF-chapter, adding a further specification. Thus, the School Participation Scales (S-PS-24/7) received their "neuropsychosocial" basis.

During the process of item construction the goal was to find questions that were easy to answer for the target group. The abstract definitions of the ICF-categories were translated into everyday school situations in order to achieve a better understanding and a more valid response style in students and parents (e.g. for the function "divided attention" a typical school situation like "listening to the teacher and writing down notes simultaneously" was used).

Additionally, we considered the design of the SPS-24/7 very carefully. At the beginning detailed written instructions explain the purpose of the questionnaire. An example item demonstrates the response format, which is an analogue rating scale. The advantage of an analogue rating scale is that it allows the respondent to fine-tune their answers. Forced choice or multiple choice formats leave the respondent with difficulties in deciding between available answer choices, which may not adequately describe their situation. Furthermore, forced choice formats often lead to psychological reactance [25]. On the other hand, open-ended answers may be disadvantageous for people with poor verbal expression skills. Therefore, the analogue rating scale seemed to be the best option. For statistical analysis the answers were transformed into a scale from 100 (meaning "the child is always able to use this function") to 0 (meaning "the child is never able to use this function"). This wording overcomes the deficit-oriented way of asking of conventional questionnaires emphasizing resource-orientation. The end points of the rating scale are further illustrated by two symbols (the symbol of a sun expresses "always", whereas the rain cloud expresses "never"). We decided against using the five-step ICF qualifier [20] because of its test-theoretical quality criteria problems regarding objectivity, validity and reliability.

In order to gather additional information, some items 
that did not correspond to the previously described format were constructed. Nevertheless, they do have a correspondence to the ICF. At the beginning of the questionnaire the prevailing mood of a patient at school was indicated. This item (as shown in Figure 1) is presented as a series of smileys that reflect five different emotional qualities (happiness, uncertainty, sadness, anxiety, anger). Students and parents chose the smiley that best reflected the prevailing mood of the child at school. The theoretical basis for this item was Plutchik's theory of the basic emotions [26]. Furthermore, the social position of a child was assessed via depicting the students in a classroom as stick figures (as also shown in Figure 1). One stick figure is standing alone in a corner, three build a small group in another corner and the rest are standing together in a large group. Both students and their parents circled the figure that best reflected the child's social position in the classroom. A question about the number of good friends at school further illustrates this aspect.

At the same time, three versions of the S-PS-24/7 were developed: one for parents, one for students attending primary school $\left(1^{\text {st }}-4^{\text {th }}\right.$ education year $)$ and one for students attending secondary school $\left(5^{\text {th }}-12^{\text {th }}\right.$ education year). The only distinction between these S-PS-24/7 versions is the phrasing of single items, which was adapted to the different age groups (with the items for elementary students having the easiest wording). The students' version of the S-PS-24/7 consists of 53 items, whereas the parents' version consists of 56 items (three items were omitted in the students' versions due to the fact that these items would require a high degree of self-reflection which cannot be expected to be fully developed in children). Questions about socio-demographic data (age, sex, school background, grades, special educational programs, education and profession of parents, etc.) were only included in the parents' version of the questionnaires in order to avoid unnecessary overlapping between the different versions).
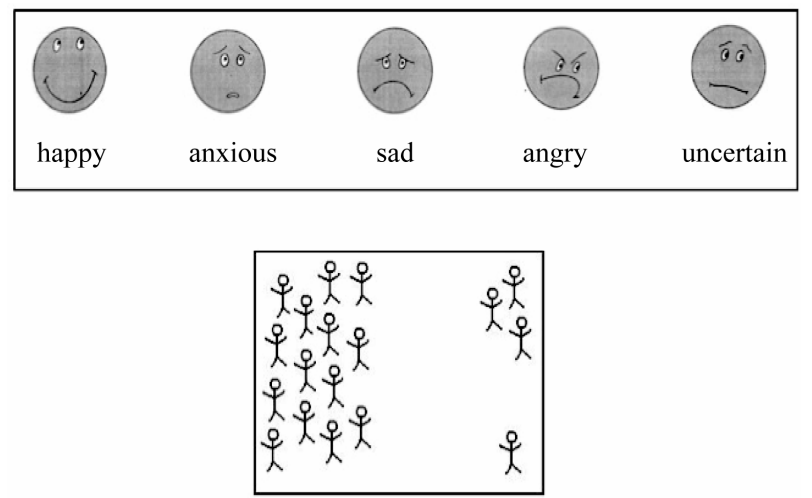

Figure 1. Prevailing mood of the patient \& social position of the child in class.
The first draft of the S-PS-24/7 was discussed with neuropsychologists, teachers, parents and students. Their feedback concerning the clarity of the items was included in the second draft (e.g. examples were added to single items in order to further clarify a question). This process was repeated one more time. The third version of the questionnaire is the one used in this study.

\subsection{Procedures}

The sample was collected at the Medical University of Vienna, Department of Pediatric and Adolescent Medicine. Inclusion criteria for children were literacy, reading comprehension, being off active treatment, school-age and attendance of the outpatient clinic for regular surveillance. After registering at the outpatient clinic the patients and their parents were informed about the goals of the study and its procedures. They received a written information sheet that was discussed together and the patients as well as their parents were given time to ask questions. Afterwards, both were asked to sign an informed consent form and to fill out the questionnaire. Fortunately, $100 \%$ of patients and parents asked agreed to take part in this study. Both groups also gave their consent to match their S-PS-24/7 answers with data from the last neuropsychological assessment of the child. At the Medical University of Vienna, the standard of care in the follow-up of patients with pediatric brain tumors includes a detailed assessment of neurocognitive as well as psychosocial aspects, which is completed on an annual basis for at least up to three years after diagnosis of the brain tumor. This assessment encompasses a standardized set of psychological tests and questionnaires, depending on the type of brain tumor and the specific question being addressed. The "core-test-battery" includes: the German version of WISC IV (HAWIK-IV) [27], AID-2 [28], VLMT [29], Trailmaking Test [30], DSS ROCF [31], KiTAP [32], TAP [33], Tower of London [34], SDQ [35] and PedsQL [36].

\subsection{Sample Characteristics}

The sample consisted of 48 patients, aged between 7 and 18 years (mean age $=12.8 ; s=3.2$ ); at the time of filling out the questionnaires, with an even ratio of $50 \%$ female and $50 \%$ male patients. Mean age at diagnosis of their brain tumor was 8.2 years $(s=4.2)$. The questionnaire was answered at a mean time of 5.7 years $(s=3.5)$ after diagnosis. In 39 cases patients and their parents filled out the S-PS-24/7. Three patients attended the outpatient clinic without their parents, and six parents filled out a form without their children (because parents attended the outpatient clinic without their children or patients had too little time left due to other medical procedures). 
Patients had been diagnosed with different types of tumors: low grade glioma in $42.2 \%$, medulloblastoma in $17.8 \%$, ependymoma in $8.9 \%$, craniopharyngioma in $8.9 \%$, pineoblastoma in $4.4 \%$, CNS primitive neuroectodermal tumor (PNET) in 4.4\%, germ cell tumor in $2.2 \%$ and other rare types of CNS tumors in $11.1 \% .46 .7 \%$ of the children had a total resection, $8.9 \%$ a subtotal resection, $20 \%$ a partial resection, $6.7 \%$ a biopsy and $4.4 \%$ had other types of surgical interventions. $13.3 \%$ of the patients had no surgery. Regarding further treatment, $6.7 \%$ of the children received chemotherapy alone, $4.4 \%$ irradiation alone and $35.6 \%$ were treated with a combination of irradiation and chemotherapy.

At the time the questionnaires were completed, $31.1 \%$ of the patients attended primary school $\left(1^{\text {st }}-4^{\text {th }}\right.$ education year), $69.2 \%$ secondary school $\left(5^{\text {th }}-8^{\text {th }}\right.$ education year: $42.2 \%$; $9^{\text {th }}-12^{\text {th }}$ education year: $27 \%$ ).

\subsection{Statistical Analysis}

Statistical analysis was performed using SPSS 16.0. In order to analyze the test-theoretical quality criteria of the S-PS-24/7, an exploratory factor analysis was conducted. A reliability analysis was also carried out. To determine the criterion validity of the scales, single items were correlated with data from parallel neuropsychological assessment using Pearson and Spearman coefficients. Furthermore, the strengths and difficulties of the patients regarding school participation were illustrated by using descriptive statistics (means and standard deviations). For illustration purposes, an independent samples t-test was used to investigate differences between low grade and high grade tumor groups.

\section{Results}

\subsection{Factor Analysis and Reliability}

All items directly addressing neuropsychological functions ( $=33$ items) were included in an exploratory factor analysis to uncover the underlying structure of the SPS-24/7 (questions asking about social support were excluded due to a different response format). The principal component analysis was selected for extraction. Then the varimax rotation was used to adjust the factor solution in order to obtain meaningful subscales. The factor analysis was conducted separately for the students' and parents' versions. As criteria for determining the number of factors, the scree plot as well as the Kaiser criterion [37] was used. Afterwards, each factor was labeled with a generic term, representing its content. Items with the highest factor loadings were used as markers for each factor.

The factor analysis of the students' version revealed 9 components for a total of 31 items, with $81 \%$ of overall explained variance, whereas the factor analysis for the parents' version resulted in 7 factors, explaining $84 \%$ of overall variance. Table 1 shows the results of the factor analyses, including the percentage of the overall explained variance as well as the ICF functions that are covered by each factor (each function is represented by one item).

To determine the reliability of the subscales, internal consistency scores for each component were calculated using Cronbach's alpha (alpha coefficients of 0.70 or higher were considered acceptable and coefficients above 0.85 preferably high [38]). As displayed in Table 1, reliability scores are acceptable for four of the nine SPS-24/7-student subscales and high for one. Regarding the seven S-PS-24/7-parents subscales, reliability scores are high for five subscales. Only those scales containing very few items and/or explaining only a small part of overall variance achieved insufficient Cronbach's alpha scores.

\subsection{Validity}

In order to investigate the validity of the S-PS-24/7, the single items were correlated with the results of the patients' neurocognitive assessment (for each function relevant test scores were chosen from the standard of care follow-up assessment described above). Pearson correlation coefficients were calculated whenever at least interval scaled measures could be assumed. In the case of ordinal measures, spearman correlation coefficients were used. In some cases validity scores could not be calculated because some ICF functions did not correspond to a certain test score from the neuropsychological assessment battery or the number of patients having received a certain test was too small (e.g. only patients with a tumor located in the cerebellum received a test for fine motor skills). The results of the validity analyses can be seen in Table 2. Only correlation coefficients $>0.30$ are considered as relevant and are therefore displayed, irrespective of their significance (which would not provide additional information due to small sample sizes in some calculations).

\subsection{Resources and Deficits Concerning School Participation}

Regarding resources and deficits, means and standard deviations were calculated for the students' and parents' versions. The scores can be seen in Table 2.

Perceptions of students and parents concerning resources in functioning seem to be similar with only slight differences in order. Students and parents reported highest scores in the domains of organization and planning, writing, calculating and impulse control. Moreover, stu- 
Table 1. Factorial structure ${ }^{\mathrm{a}}$ of the S-PS-24/7 (students' and parents' versions).

\begin{tabular}{|c|c|c|c|c|c|c|}
\hline & \multicolumn{3}{|c|}{ S-PS-24/7 students } & \multicolumn{3}{|r|}{ S-PS-24/7 parents } \\
\hline Component & $\begin{array}{l}\text { Explained } \\
\text { variance }\end{array}$ & $\begin{array}{l}\text { Cronbach's } \\
\text { alpha }\end{array}$ & ICF functions & $\begin{array}{l}\text { Explained } \\
\text { variance }\end{array}$ & $\begin{array}{l}\text { Cronbach's } \\
\text { alpha }\end{array}$ & ICF functions \\
\hline 1 & $37.86 \%$ & 0.89 & $\begin{array}{l}\text { Organization and planning, } \\
\text { calculating, watching, listening, } \\
\text { reading, writing }\end{array}$ & $43.44 \%$ & 0.91 & $\begin{array}{l}\text { Psychomotor control, pace of thought, } \\
\text { memory functions (capacity), time } \\
\text { management, dividing attention, } \\
\text { organization and planning }\end{array}$ \\
\hline 2 & $10.17 \%$ & 0.82 & $\begin{array}{l}\text { Pace of thought, time management, } \\
\text { dividing attention, making decisions }\end{array}$ & $12.80 \%$ & 0.89 & $\begin{array}{l}\text { Energy level, hand and arm use, moving } \\
\text { around, calculating, problem solving, } \\
\text { handling stress, insight }\end{array}$ \\
\hline 3 & $6.79 \%$ & 0.85 & $\begin{array}{l}\text { Retrieval of memory, long-term } \\
\text { memory, short-term memory }\end{array}$ & $9.90 \%$ & 0.93 & $\begin{array}{l}\text { Focused attention, sustaining attention, } \\
\text { watching, listening, retrieval of memory, } \\
\text { quality of psychomotor functions, form of } \\
\text { thought, long-term memory }\end{array}$ \\
\hline 4 & $5.98 \%$ & 0.79 & $\begin{array}{l}\text { Undertaking multiple tasks, fine } \\
\text { hand use-writing, fine hand } \\
\text { use-drawing, quality of psychomotor } \\
\text { functions }\end{array}$ & $6.31 \%$ & 0.86 & $\begin{array}{l}\text { Working memory, short-term memory, } \\
\text { reading, regulation of emotion, cognitive } \\
\text { flexibility }\end{array}$ \\
\hline 5 & $4.91 \%$ & 0.79 & $\begin{array}{l}\text { Energy level, sustaining attention, } \\
\text { cognitive flexibility }\end{array}$ & $4.69 \%$ & 0.67 & $\begin{array}{l}\text { Impulse control, undertaking multiple tasks, } \\
\text { making decisions, }\end{array}$ \\
\hline 6 & $4.28 \%$ & 0.80 & $\begin{array}{l}\text { Memory functions (capacity), hand } \\
\text { and arm use, focused attention, } \\
\text { problem solving }\end{array}$ & $3.81 \%$ & 0.63 & $\begin{array}{l}\text { Fine hand use-writing, fine hand } \\
\text { use-drawing }\end{array}$ \\
\hline 7 & $4.03 \%$ & 0.54 & Psychomotor control, handling stress & $3.38 \%$ & 0.91 & Looking after one's health, writing \\
\hline 8 & $3.73 \%$ & 0.61 & $\begin{array}{l}\text { Looking after one's health, regulation } \\
\text { of emotion }\end{array}$ & & & \\
\hline 9 & $3.26 \%$ & 0.62 & Moving around, impulse control & & & \\
\hline
\end{tabular}

${ }^{\mathrm{a}}$ Items with the highest factor loadings are marked in bold.

dents perceived undertaking multiple tasks and looking after one's health as resources as well.

Concerning deficits, students and parents reported lowest scores in the domains of divided attention, memory functions (capacity), psychomotor control and time management. Students rated sustained attention, problem solving and fine motor control as being further deficits.

\subsection{Emotion and Social Position at School}

$64.3 \%$ of the students and $53.3 \%$ of the parents reported happiness to be the prevailing mood at school. The second most common mood was anxiety (students $21.4 \%$; parents $22.2 \%$ ), followed by uncertainty (students $7.1 \%$; parents $11.1 \%$ ), sadness (students $4.8 \%$; parents $4.4 \%$ ) and anger (students $3.2 \%$; parents $0 \%$ ).

Regarding the social position in the classroom, $71.4 \%$ of the students perceived themselves as being integrated within the classroom community, whereas $64.4 \%$ of the parents rated their child as being fully integrated. To the contrary, $2.4 \%$ of the students seemed to be loners according to their own views (and 2.2\% according to the parents). The rest $(26.2 \%$ of the students in their own view and $28.9 \%$ in the parents' view) seemed to be only partially integrated. Asked about the number of friends in class, $11.2 \%$ of the students (and $11.4 \%$ of the parents) reported having only one friend or no friends at all.

On the other hand, $59.5 \%$ of the students (and $43.2 \%$ of the parents) reported having four or more friends in class. To further illustrate the social aspect, patients with a low grade glioma were compared to patients with medulloblastoma (being the most common tumor types in the sample). Students having suffered from a low grade glioma tended to have more friends than patients with a medulloblastoma. As can be seen from Table 3, a significant difference between the two patient groups could only be found in the students' rating ( $\mathrm{t}$-test, $\mathrm{p}=0.01$ ).

\section{Discussion}

The present study aimed to develop and evaluate an ICF-based assessment instrument (the School Participation Scales 24/7) to gather knowledge about functioning and participation in everyday school life of pediatric brain tumor patients. While the ICF only offered the conceptual framework without intending to be a practical tool itself, this approach facilitated the implementation of the ICF into clinical practice. Formerly, uni-dimensional scores like the IQ served as outcome measures. This is no longer necessary since more and more neuropsychologi- 
Table 2. Results of students' and parents' ratings ${ }^{\mathrm{a}}$ and validity analysis ${ }^{\mathrm{b}}$.

\begin{tabular}{|c|c|c|c|c|c|c|}
\hline \multirow[b]{2}{*}{ ICF classification } & \multicolumn{3}{|c|}{ S-PS-24/7 students } & \multicolumn{3}{|c|}{ S-PS-24/7 parents } \\
\hline & Mean & SD & Validity & Mean & $\mathrm{SD}$ & Validity \\
\hline Sustaining attention & 68.0 & 26.8 & $0.52 \mathrm{KI} / \mathrm{TAP}$ focused attention (errors) & 70.3 & 23.1 & $0.34 \mathrm{KI} / \mathrm{TAP}$ focused attention (missings) \\
\hline Dividing attention & 68.5 & 29.0 & $\begin{array}{l}0.98 \mathrm{KI} / \mathrm{TAP} \text { focused attention (errors) } \\
0.38 \mathrm{KI} / \mathrm{TAP} \text { divided attention } \\
\text { (missings-auditory) }\end{array}$ & 59.8 & 29.7 & $\begin{array}{l}0.76 \mathrm{KI} / \mathrm{TAP} \text { divided attention } \\
\text { (reaction time auditory) } \\
0.46 \mathrm{KI} / \mathrm{TAP} \text { divided attention } \\
\text { (reaction time visual) }\end{array}$ \\
\hline Short-term memory & 69.9 & 32.1 & 0.48 VLMT (recognition) & 74.3 & 22.8 & $\begin{array}{l}0.50 \text { VLMT (delayed recall) } \\
0.46 \text { ROCF (immediate recall) }\end{array}$ \\
\hline Long-term memory & 71.1 & 27.4 & $\begin{array}{l}0.59 \text { VLMT (delayed recall) } \\
0.62 \text { ROCF (immediate recall) }\end{array}$ & 75.6 & 21.3 & 0.39 VLMT (delayed recall) \\
\hline Retrieval of memory & 73.6 & 26.7 & 0.58 VLMT (delayed recall) & 73.2 & 24.7 & $\begin{array}{l}0.36 \text { ROCF (delayed recall) } \\
0.33 \text { VLMT (delayed recall) }\end{array}$ \\
\hline $\begin{array}{l}\text { Memory functions } \\
\text { (capacity) }\end{array}$ & 65.5 & 29.0 & 0.58 VLMT (trial $1-5$ ) & 61.6 & 28.4 & $\begin{array}{l}0.36 \text { ROCF (delayed recall) } \\
0.36 \text { AID } 2 \text { (subtest } 5 \mathrm{a} \text { ) }\end{array}$ \\
\hline $\begin{array}{l}\text { Quality of psychomotor } \\
\text { functions }\end{array}$ & 70.4 & 26.1 & -0.82 WISC IV (processing speed) & 71.3 & 26.0 & -0.60 Trailmaking (switching) \\
\hline Regulation of emotion & 72.9 & 25.9 & - & 71.2 & 25.9 & $0.41 \mathrm{SDQ}$ (total difficulties) \\
\hline Pace of thought & 69.1 & 27.2 & 0.52 Trailmaking (number) & 62.8 & 25.3 & 0.46 Trailmaking (letter) \\
\hline Form of thought & - & - & - & 69.9 & 25.7 & 0.46 WISC IV (perceptional reasoning) \\
\hline Organization and planning & 84.4 & 24.6 & 0.34 ROCF (copy, errors) & 78.6 & 24.5 & $-0.54 \mathrm{ToL}$ \\
\hline Time management & 67.7 & 31.2 & $\begin{array}{l}0.60 \text { AID } 2 \text { (subtest } 3 \text { ) } \\
0.47 \text { ROCF (copy) } \\
0.39 \text { ToL }\end{array}$ & 60.3 & 28.8 & 0.45 AID 2 (subtest 3 ) \\
\hline Cognitive flexibility & 72.6 & 27.6 & $\begin{array}{l}\text { 0.40 Trailmaking (switching) } \\
0.68 \text { KITAP flexibility (reaction time) }\end{array}$ & 77.6 & 24.5 & 0.48 KITAP flexibility (reaction time) \\
\hline Working memory & 75.5 & 27.5 & 0.94 AID 2 (subtest 5a) & 72.1 & 25.0 & $\begin{array}{l}0.75 \text { WISC IV (working memory) } \\
0.55 \text { VLMT (memory span) } \\
\text { 0.40 TAP working memory } \\
\text { (reaction time) }\end{array}$ \\
\hline Insight & - & - & - & 73.6 & 24.9 & - \\
\hline Problem solving & 68.4 & 25.5 & 0.38 ROCF (copy) & 64.3 & 25.8 & 0.56 WISC IV (matrix reasoning,) \\
\hline Watching & 77.3 & 24.8 & - & 80.2 & 20.5 & - \\
\hline Listening & 76.9 & 26.7 & - & 79.9 & 21.5 & - \\
\hline Reading & 76.9 & 29.1 & - & 78.5 & 28.5 & - \\
\hline Writing & 78.6 & 27.9 & - & 83.2 & 20.3 & - \\
\hline Calculating & 83.5 & 22.9 & - & 79.0 & 21.4 & 0.36 AID 2 (subtest 3 ) \\
\hline Making decisions & 72.7 & 28.5 & - & 73.7 & 24.0 & - \\
\hline Impulse control & 86.8 & 22.8 & $\begin{array}{l}0.56 \mathrm{KI} / \mathrm{TAP} \text { flexibility } \\
\text { (reaction time SD) } \\
0.43 \mathrm{SDQ} \text { hyperactivity score }\end{array}$ & 83.6 & 22.9 & $0.51 \mathrm{KI} / \mathrm{TAP}$ divided attention (errors) \\
\hline Undertaking multiple tasks & 78.8 & 28.7 & $\begin{array}{l}0.54 \mathrm{KI} / \mathrm{TAP} \text { divided attention (errors) } \\
0.40 \mathrm{ROCF} \text { (copy, errors) }\end{array}$ & 74.3 & 26.9 & $\begin{array}{l}0.40 \mathrm{KI} / \mathrm{TAP} \text { divided attention } \\
\text { (reaction time, visual) }\end{array}$ \\
\hline Energy level & 75.6 & 26.7 & - & 71.6 & 27.8 & - \\
\hline Handling stress & 72.9 & 27.4 & - & 63.1 & 27.7 & - \\
\hline Looking after one's health & 78.0 & 29.5 & - & 74.1 & 24.5 & - \\
\hline Fine hand use-writing & 64.8 & 35.2 & - & 63.2 & 34.4 & - \\
\hline Fine hand use - drawing & 71.1 & 29.8 & - & 70.7 & 24.7 & - \\
\hline Hand and arm use & 76.1 & 29.0 & - & 73.5 & 27.2 & - \\
\hline Moving around & 70.2 & 33.9 & - & 70.1 & 29.5 & - \\
\hline
\end{tabular}

${ }^{\mathrm{a}}$ Analogue rating scale: scores between 0 - 100; high scores = resources, low scores $=$ deficits; ${ }^{\mathrm{b}}$ Pearson or Spearman correlation between ICF function and neuropsychological test score; tests used for analysis: WISC IV, AID 2, VLMT, D-KEFS Trailmaking-Test, DSS ROCF, KI/TAP $($ KITAP = version for children, TAP = version for adults), ToL, SDQ. Test scores were percentile ranks except for SDQ (grading given by manual was used). If a certain test gives more than one score the used test score is indicated after the name of the test. 
Table 3. Comparison of low grade glioma patients and medulloblastoma patients: average number of friends.

\begin{tabular}{lcc}
\hline & \multicolumn{2}{c}{ Number of friends (mean) } \\
\cline { 2 - 3 } Tumor group & Students' view & Parents' view \\
\hline Patients with low grade glioma & $3.78(1.26)$ & $3.56(1.50)$ \\
Patients with medulloblastoma & $2.00(1.77)$ & $2.75(1.49)$ \\
p-value (independent samples t-test) & 0.01 & 0.22 \\
\hline
\end{tabular}

cal tests exist in order to assess neurocognitive functioning. The S-PS-24/7 now combines neuropsychological test data with self- and parent reports and thus fills the information gap that was left by using IQ scores only.

The construction of the S-PS-24/7 can be regarded as successful. Test-theoretical analyses revealed 9 components in the students' version and 7 components in the parents' version. This is satisfactory in terms of overall explained variance $(81 \%$ vs. $84 \%)$. In both versions, reliability scores for the components illustrate the precision, even if single subscales could still be improved. Regarding the validity of the S-PS-24/7, the evaluation shows moderate but substantial correlations with corresponding scores from a neuropsychological assessment battery. This implies that the S-PS-24/7 items do measure a certain amount of variance beyond neuropsychological tests for which the participation aspect is a plausible explanation. However, the latent factors found in this study do not mirror the structure given by the ICF. This may be due to too few items for each function set. On the other hand, it seems obvious to assume that different ICF functions are linked to each other.

Body functions may especially influence participation in everyday life (which is in fact postulated by the ICF framework and was investigated by Granlund [39]). This hypothesis is also supported by results showing items measuring body functions as well as items assessing domains of participation scoring on the same component. Moreover, [39] showed that an individual-based participation profile is preferable to a group approach. Therefore, it seems obvious that a factor analysis would reveal different results depending on the individuals included.

In terms of neurocognitive outcome using the SPS-24/7 as a measurement instrument, the results are compatible with previous findings showing a wide variety of possible deficits in pediatric brain tumor patients. Once more, the results indicate global outcome measures like the IQ - as stated above - being of no use in describing participation. Additionally, the present findings show a large number of patients to be suffering from the above mentioned illness-related problems. This is supported by approximately half of the parents reporting happiness not being the prevailing mood of the patients at school. Moreover, social integration in the classroom seems to also be affected.
In summary, we found a way to describe the specific needs of this distinct patient group. By doing so, the advantages of an ICF-based approach became obvious:

1) The S-PS-24/7 provides a common basis for communicating the neurocognitive outcome of pediatric brain tumor patients.

2) The S-PS-24/7 offers the possibility to directly implement the ICF into clinical practice.

3) The response format of the S-PS-24/7 overcomes the test-theoretical problems in the ICF qualifier [20] using an analogue rating scale, but can still be transformed into the five-step format.

4) The S-PS-24/7 combines different perspectives (students and parents) and allow a direct comparison of these data with data from neurocognitive assessments.

5) Due to the universal language of the ICF, the S-PS-24/7 could be used for other groups of patients at risk for neurocognitive deficits as well. Moreover, the S-PS-24/7 might even be useful as a screening instrument for healthy children and adolescents.

However, several limitations of this study need to be discussed. First, the collected data cannot be generalized to other populations. The sample consists of many different tumor types, students of different ages and various onsets of illness. It might be possible that reliability and validity as well as indicators of neurocognitive outcome are less precise in a more homogenous group of patients.

Second, we do not yet know in what way healthy children and adolescents would answer the questions and can therefore not foresee the differentiation quality of the S-PS-24/7. However, ongoing studies are promising.

Finally, addressing future prospects, despite promising reliability and validity scores there is still room for improvement. The validity of the ICF-model as item basis has to be investigated by performing a confirmatory factor-analysis. A second version of the S-PS-24/7 is in development and will further emphasize the environmental aspect of the ICF by including more questions. A healthy norm group will provide further insight into participation elements that are probably universal to children and adolescents and into those elements that are unique to CNStumor patients. To enhance the significance of the different perspectives, the teachers' view will be included as well and further studies will investigate similarities and differences in these groups. 
The practical application of the S-PS-24/7 proved to be promising so far in our department and has found its way into a standard of care neuropsychological assessment. The S-PS-24/7, in combination with the results of a neuropsychological test-battery, enable differentiated counseling of patients, parents and teachers with the aim of facilitating participation in school life and providing special support services to the patients. In many cases, the S-PS-24/7 already illustrated the patients' and the parents' perspectives in a way that was crucial for further interventions. This is eventually the long-term objective of our future research on school reintegration in pediatric neurooncology: the development of specific intervention programs, based on distinct functions and personal as well as environmental factors to improve participation in everyday life of the young patients.

\section{REFERENCES}

[1] M. Barrera, A. K. Shaw, K. N. Speechley, et al., "Educational and Social Late Effects of Childhood Cancer and Related Clinical Personal, and Familial Characteristics," Cancer, Vol. 104, No. 8, 2005, pp. 1751-1760. doi:10.1002/cncr.21390

[2] P. A. Mitby, L. L. Robinson, J. A. Whitton, et al., "Utilization of Special Education Services and Educational Attainment among Long-Term Survivors of Childhood Cancer," Cancer, Vol. 97, No. 4, 2003, pp. 1115-1126. doi:10.1002/cncr.11117

[3] H. Stam, M. A. Grootenhuis and B. F. Last, "The Course of Life of Survivors of Childhood Cancer," Psycho-Oncology, Vol. 14, No. 3, 2005, pp. 227-238.

doi:10.1002/pon.839

[4] K. Konrad, S. Gauggel and H. T. Jansen, "Hirntumorerkrankungen im Kindesalter: Kognitive, Affektive und Psychosoziale Langzeitfolgen," Kindheit und Entwicklung, Vol. 7, No. 3, 1998, pp. 154-162.

[5] V. A. Anderson, T. Godber, E. Smibert, et al., "Cognitive and Academic Outcome Following Cranial Irradiation and Chemotherapy in Children: A Longitudinal Study," British Journal of Cancer, Vol. 82, No. 2, 2000, pp. 255262.

[6] T. S. Reimers, S. Ehrenfels, E. L. Mortensen, et al., "Cognitive Deficits in Long-Term Survivors of Childhood Brain Tumors: Identification of Predictive Factors," Pediatric Blood and Cancer, Vol. 40, No. 1, 2003, pp. 26-34.

[7] G. Poggi, M. Liscio, S. Galbiati, et al., "Brain Tumors in Children and Adolescents: Cognitive and Psychological Disorders at Different Ages," Psycho-Oncology, Vol. 14, No. 5, 2005, pp. 386-395. doi:10.1002/pon.855

[8] J. Grill, D. Viguier, V. Kieffer, et al., "Critical Risk Factors for Intellectual Impairment in Children with Posterior Fossa Tumors: The Role of Cerebellar Damage," Journal of Neurosurgery (Pediatrics), Vol. 101, No. 2, 2004, pp. 152-158. doi:10.3171/ped.2004.101.2.0152
[9] C. Rønning, K. Sundet, B. Due-Tønnessen, et al., "Persistent Cognitive Dysfunction Secondary to Cerebellar Injury in Patients Treated for Posterior Fossa Tumors in Childhood," Pediatric Neurosurgery, Vol. 41, No. 1, 2005, pp. 15-21. doi: $10.1159 / 000084860$

[10] B. J. Spiegler, E. Bouffet, M. L. Greenberg, et al., "Change in Neurocognitive Functioning after Treatment with Cranial Radiation in Childhood," Journal of Clinical Oncology, Vol. 22, No. 4, 2004, pp. 706-713. doi:10.1200/JCO.2004.05.186

[11] R. K. Mulhern, S. L. Palmer, T. E. Merchant, et al., "Neurocognitive Consequences of Risk-Adapted Therapy for Childhood Medulloblastoma," Journal of Clinical Oncology, Vol. 23, No. 24, 2005, pp. 5511-5519. doi:10.1200/JCO.2005.00.703

[12] B. J. Nagel, D. C. Delis, S. L. Palmer, et al., "Early Patterns of Verbal Memory Impairment in Children Treated for Medulloblastoma," Neuropsychology, Vol. 20, No. 1, 2006, pp. 105-112. doi:10.1037/0894-4105.20.1.105

[13] E. N. Kiehna, R. K. Mulhern, C. Li, X. Xiog, et al., "Changes in Attentional Performance of Children and Young Adults with Localized Primary Brain Tumors after Conformal Radiation Therapy," Journal of Clinical Oncology, Vol. 24, No. 33, 2006, pp. 5283-5290. doi:10.1200/JCO.2005.03.8547

[14] D. J. Mabbott, L. Penkman, A. Witol, et al., "Core Neurocognitive Functions in Children Treated for Posterior Fossa Tumors," Neuropsychology, Vol. 22, No. 2, 2008, pp. 159-168. doi:10.1037/0894-4105.22.2.159

[15] B. Rupp, T. Pletschko, U. Leiss, et al., "Do We Still Need IQ Scores? Misleading Interpretations of Neurocognitive Outcome in Paediatric Patients with Medulloblastoma [Abstract]," SIOP Abstract Book 2008: 40 ${ }^{\text {th }}$ Congress of the International Society of Paediatric Oncology, Berlin, 2-6 October 2008.

[16] K. E. Robinson, J. F. Kuttesch, J. E. Champion, et al., “A Quantitative Meta-Analysis of Neurocognitive Sequelae in Survivors of Pediatric Brain Tumors," Pediatric Blood and Cancer, Vol. 55, No. 3, 2010, pp. 525-531. doi: $10.1002 / \mathrm{pbc} .22568$

[17] K. Vannatta, M. A. Gartstein, A. Short, et al., "A Controlled Study of Peer Relationships of Children Surviving Brain Tumors: Teacher, Peer and Self Ratings," Journal of Pediatric Psychology, Vol. 23, No. 5, 1998, pp. 279287. doi:10.1093/jpepsy/23.5.279

[18] N. Winick, "Neurocognitive Outcome in Survivors of Pediatric Cancer," Current Opinion in Pediatrics, Vol. 23, No. 1, 2011, pp. 27-33. doi:10.1097/MOP.0b013e32834255e9

[19] K. S. Canter and M. C. Roberts, "A Systematic and Quantitative Review of Interventions to Facilitate School Reentry for Children with Chronic Health Conditions," Journal of Pediatric Psychology, Vol. 37, No. 10, 2012, pp. 1065-1075. doi:10.1093/jpepsy/jss071

[20] World Health Organisation, "International Classification of Functioning, Disability and Health (ICF)," WHO, Genf, 2001.

[21] D. Ajovalasit, C. Vago, A. Usilla, et al., "Use of ICF to 
Describe Functioning and Disability in Children with Brain Tumors," Disability and Rehabilitation, Vol. 31, No. s1, 2009, pp. 100-107. doi:10.3109/09638280903317856

[22] H. McConachie, A. F. Colver, R. J. Forsyth, et al., "Participation of Disabled Children: How Should It Be Characterised and Measured?" Disability and Rehabilitation, Vol. 28, No. 18, 2006, pp. 1157-1164. doi:10.1080/09638280500534507

[23] R. Ehrenfors, L. Borell and H. Hemmingsson, “Assessments Used in School-Aged Children with Acquired Brain Injury-Linking to the International Classification of Functioning, Disability and Health," Disability and Rehabilitation, Vol. 31, No. 17, 2009, pp. 1392-1401. doi:10.1080/09638280802621366

[24] G. Stucki, N. Kostanjsek, B. Ustün, et al., "ICF-Based Classification and Measurement of Functioning," European Journal of Physical and Rehabilitation Medicine, Vol. 44, No. 3, 2008, pp. 315-328.

[25] K. D. Kubinger, "Psychologische Diagnostik-Theorie und Praxis Psychologischen Diagnostizierens," Auflage, Hogrefe, Göttingen, 2009.

[26] R. Plutchik, "The Emotions: Facts, Theories, and a New Model," Random House, New York, 1962.

[27] F. Petermann and U. Petermann, "HAWIK ${ }^{\circledR}-I V$. Hamburg-Wechsler-Intelligenztest für Kinder-IV. Übersetzung und Adaption der WISC-IV ${ }^{\mathbb{R}}$ von David Wechsler," Huber, Bern, 2007.

[28] K. D. Kubinger and E. Wurst, "AID 2. Adaptives Intelligenz Diagnostikum 2," Version 2.1, Beltz, Göttingen, 2000.

[29] C. Helmstaedter, M. Lendt and S. Lux, "VLMT. Verbaler Lernund Merkfähigkeitstest,” Beltz, Göttingen, 2001.

[30] D. C. Delis, E. Kaplan and J. H. Kramer, "Delis-Kaplan Executive Function System (D-KEFS)," The Psychologi- cal Corporation, San Antonio, 2001.

[31] J. H. Bernstein and D. P. Waber, "DSS ROCF. Developmental Scoring System for the Rey-Osterrieth Complex Figure: Professional manual," Psychological Assessment Resources, Inc, Lutz, 1996.

[32] P. Zimmermann, M. Godan and B. Fimm, "KITAP. Testbatterie zur Aufmerksamkeitsprüfung für Kinder (Version 1.4) [Computer Software]," Psytest, Herzogenrath, 2007.

[33] P. Zimmermann and B. Fimm, "TAP. Testbatterie zur Aufmerksamkeitsprüfung (Version 2.2) [Computer Software]," Psytest, Herzogenrath, 2009.

[34] O. Tucha and K. W. Lange, "TL-D. Turm von LondonDeutsche Version,” Hogrefe, Göttingen, 2004.

[35] R. Goodman, "The Extended Version of the Strengths and Difficulties Questionnaire as a Guide to Child Psychiatric Caseness and Consequent Burden," Journal of Child Psychology and Psychiatry, Vol. 40, No. 5, 1999, pp. 791-801. doi:10.1111/1469-7610.00494

[36] J. W. Varni, M. Seid and P. Kurtin, "PedsQL" 4.0: Reliability and Validity of the Pediatric Quality of Life Inventory ${ }^{\mathrm{TM}}$ Version 4.0 Generic Core Scales in healthy and patient populations," Medical Care, Vol. 39, No. 8, 2001, pp. 800-812. doi:10.1097/00005650-200108000-00006

[37] H. F. Kaiser and K. W. Dickman, "Analytic Determination of Common Factors," American Psychologist, Vol. 14, No. 1, 1959, pp. 425-441.

[38] K. Westhoff, L. J. Hellfritsch, L. F. Hornke, et al., (Hrsg.), "Grundwissen für die Berufsbezogene Eignungsbeurteilung nach DIN 33430," Pabst, Lengerich, 2004.

[39] M. Granlund, L. Eriksson and R. Ylvén, "Utility of International Classification of Functioning, Disability and Health's Participation Dimension in Assigning ICF Codes to Items from Extant Rating Instruments," Journal of Rehabilitation Medicine, Vol. 36, No. 3, 2004, pp. 130137. doi:10.1080/16501970310021707 